\title{
The Impact of Packaging Designs on Consumer Buying Behaviour of FMCG during the Hyperinflationary and After the Dollarisation Era in Zimbabwe
}

\begin{tabular}{|c|c|}
\hline $\begin{array}{l}\text { Godwell Karedza } \\
\text { Mike Sikwila }\end{array}$ & 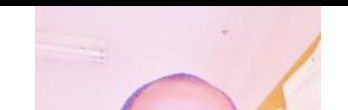 \\
\hline $\begin{array}{l}{ }^{1} \text { Department of International Marketing Chinhoyi University of Technology, Chinhoyi, } \\
\text { Zimbabwe } \\
{ }^{2} \text { Department of Consumer Science Chinhoyi University of Technology, Chinhoyi, Zimbabwe }\end{array}$ & ( Corresponding Author) \\
\hline
\end{tabular}

\begin{abstract}
Purpose - The main thrust of this research paper is to investigate the effect of designs that come with a package and how they influence consumer purchasing habit of FMCG products in Zimbabwe during and after the multicurrency period. The objectives of the research was to ascertain the major effect of packaging designs on consumer purchasing pattern of FMCG goods in Zimbabwe, to establish the major function of packaging on FMCG products and to examine the salient effect of other factors that can be controlled and that cannot be controlled (such as price, quality, promotion, socio cultural environment, social class, personality and self concept, attitudes and learning) on the purchasing pattern of consumer on FMCG goods during and after the multi-currency period in Zimbabwe. Design/ methodology/ approach - The researcher adopted the descriptive survey and exploratory research designs to gather data from the retail sector. The research was conducted in Harare Zimbabwe where most of the retail outlets are mainly concentrated. A study sample of 47 respondents from the retail sector was used targeting firms in the FMCG sector. Data to answer research problem was obtained through an in-depth interviews and questionnaires. 5 policy makers were interviewed while 42 questionnaires were sent to retail managers and of which 32 were then returned. The target samples were guided with a questionnaire with closed and open ended questions. Respondents were Stratified and conveniently selected. Findings - The findings revealed that, the element with the most influential factor on purchasing habit of FMCG products is printed information as indicated by more respondents. Thus the correct message will sell a product hence designers and product strategists must think first on all messages they are sending to consumers. Printed information has more bearing on the buying pattern of consumers, followed by size. Background image, colour and font styles were also pointed out as having an effect on the buying behaviour of FMCG products. Font styles however have the least effect the purchasing behaviour of consumers. This corresponds with Deliya and Parmar (2012)study which concluded that font style has the least effect as compared to all the packaging elements. It should be concluded that size and material are the visual elements mainly considered by customers when buying products while product information is also the main verbal elements having an effect on consumer decision making. Conclusively packaging elements are perceived to be an element of the product. The research also revealed that, during and after the multi-currency period, consumers in Zimbabwe preferred to purchase more of foreign packaged products than local packed products.
\end{abstract}

Keywords: Packaging, FMCG (Fast Moving Consumer Goods), Consumer buying behaviour, Imports.

\section{Contents}

1. Introduction

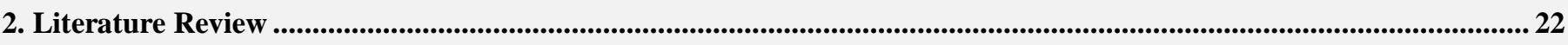

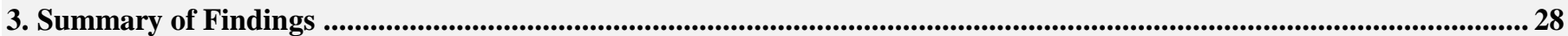

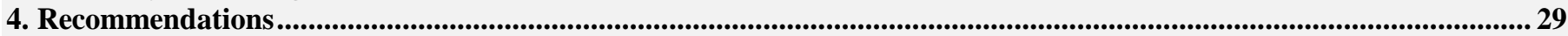

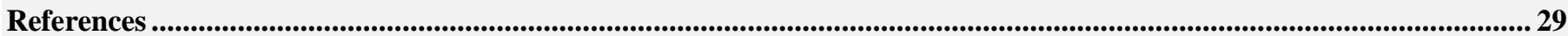

Citation | Godwell Karedza; Mike Sikwila (2017). The Impact of Packaging Designs on Consumer Buying Behaviour of FMCG during the Hyperinflationary and After the Dollarisation Era in Zimbabwe. Asian Journal of Social Sciences and Management Studies, 4(1): 20-30.

DOI:

$\operatorname{ISSN}(\mathbf{E})$

ISSN(P) :

10.20448/journal.500/2017.4.1/500.1.20.30 $\geqslant$ Crossref

This work is licensed under a Creative Commons Attribution 3.0 License (cc) EY

Contribution/Acknowledgement: All authors contributed to the conception and design of the study.

Funding:

Competing Interests

This study received no specific financial support.

Transparency: The authors declare that they have no conflict of interests.

The authors confirm that the manuscript is an honest, accurate, and transparent account of the study was reported; that no vital features of the study have been omitted; and that any discrepancies from the study as planned have been explained.

History: Received: 10 December 2015/ Revised: 7 November 2016/ Accepted: 24 November 2016/ Published: 5 December 2016 


\section{Introduction}

This research focuses on how packaging design impacts on consumer buying behaviour of fast moving consumer goods (FMCG) in Zimbabwe during and after the dollarization era. The research emanates from the differences in packaging designs of local and imported FMCG products. The research seeks to find out what determines consumer buying habit on foreign packaged products as compared to local products in the period, before, and after the dollarization era in Zimbabwe.

\subsection{The background}

The post independence era in Zimbabwe was characterised by the development of local industries including the FMCG sector. In this period a number of local FMCG products were being displayed in supermarket shelves and competition was mainly among players in the local FMCG sector until 2007 when there was hyper-inflation in Zimbabwe forcing many companies out of business. Local FMCG products that used to be on supermarket shelves were replaced by imports and others completely vanished. These imports however came with different packaging designs of attractiveness than what local manufacturers offered in line with size, colour, and materials. In 2009 Zimbabwe adopted the multi-currency system to replace the local currency, it is during this period when local industries started to revive and the local FMCG products began flocking back into the supermarkets shelves at the back of cutthroat competition from the imports. Zimbabwe products stated facing tough competition from imports as importers can as well afford to sell better appealing products than those of local manufactures. Technology change is a key driver and in enhancing growth in a competitive business environment today. Change of technology is enabling some manufacturers to produce more appealing, attractive designs than those being produced locally. This change of technology is a major threat to local manufacturers in Zimbabwe in the FMCG industry.

Kangasharju (2000) highlights that competitive concentration in conjunction with actions and strategies of rivals have greater effects on the survival of companies and companies who fail to enact the appropriate market facing strategies may collapse. Therefore a proper knowledge of the motives of rivals, the right marketing strategy and the corresponding action to the competition are crucial for the survival of any organisation. Thus, it is important to be abreast with changinging game plan of competitors and try to adjust the products packaging designs to meet the same standards in the international markets or to outwit the competitor completely so as to survive in this dynamic environment where customer tastes are always changing.

Before the period denoted as World War II, the main purpose of packaging of FMCG goods was to standardize, protect the product and ensuring that the product is safe during transportation and distribution, thus this is not a new concept. The main purpose of packaging was to ensure the preservation and transportation of the goods and even for ease-of-use by the consumers but packaging design was typically left to technicians. However at the end of World War II companies became more interested in mass production and development of packaging and invested more in marketing and promotional tools as a means of converting customers minds to purchase their products. As a result many manufacturers of FMCG goods envisaged packaging as one of the job of a silent sales man. Industrial revolution that took place at this time meant increased attention to packaging and with socio-economic changes that were taking place around the world consumers were becoming better educated and thus their expectations on package designs and their trust on them increased as well. Packaging materials that were used for FMCG products include rigid and fixed plastic, metal, paper and glass.

Deliya and Parmar (2012) assert that packaging design is seen as a vehicle for communication and branding and this has received wide spread attention. Kuvykaite et al. (2009) referred to packaging design as a silent salesman that shapes consumer perception and becomes a determining factor in point of purchase decision. Thus packaging is one of the salient ingredients determining un planned purchasing behavior of customers. In line with that, Kotler (2002) highlights that packaging have an attractive bearing, thus it influences purchasing, perception about the product. Packaging also gives value to products, thus enhancing its merchandise (Underwood et al., 2001). On the other hand Deliya and Parmar (2012) highlight that packaging forms the end of 'promotion chain' and is close in time to the actual purchase.

Consequently the researcher seeks to establish the effect of packaging design on consumer buying behavior, the question is, to what extent do packaging designs impacts on customer orientation towards local FMCG products?

\subsection{The study Problem}

The Imports products termed FMCG come with different packaging designs than those of local FMCG products. At the same time local FMCG products are on a cutthroat competition to those favouring products with import packaging designs more than those with local packaging designs. Thus, this has motivated the researcher to explore the effect of packaging design on consumer buying behaviour of FMCG products in Zimbabwe during and after the multi-currency period in Zimbabwe.

\subsection{Research Objectives}

The research aims:

1. To examine the impact of packaging designs on consumer purchasing habit of FMCG goods before, during and after the dollarization era in Zimbabwe.

2. To establish the major role of packaging on FMCG products.

3. To examine the effect of other factors that can be controlled and that cannot be controlled (such as price, quality, promotion, socio cultural environment, social class, personality and self concept, attitudes and learning) on the purchasing pattern and habit of FMCG products in Zimbabwe. 


\subsection{Justification}

As a result of increasing sophistication of the modern consumer, the growing of self-service and changing consumers' lifestyle as a result of dollarisation in Zimbabwe, is a course for concern, moreover, the interest in packaging as a promotional mechanism and stimulator of impulsive buying is growing increasingly important in many retail shops and is seemingly one of the influencers of consumer decision making. Thus, retailers may benefit from this study. The research may also helps scholars to gain an in depth practical knowledge on how packaging act as a silent salesman in an increasing competitive environment. This study is important as policy makers may use the results of this study for their advisory purposes so as to ensure that retailers benchmark their packaging materials with the leading countries.

\section{Literature Review}

\subsection{Packaging}

Deliya and Parmar (2012) highlight that the definition of packaging vary and range from being simple and functionally focused to more extensive, holistic interpretations. The aforementioned assert that packaging act as an extrinsic value of the good. Kotler (2000) asserts that packaging includes all activities that are involved until the final package is brought out. Packaging is also seen as an attribute of the final product. Arens (1996) highlights that packaging is the container which covers the manufactured product and ultimately enhances the final product through, colour, shape, labeling and materials used.

\subsubsection{Package Design}

Orth and Malkewitz (2008) highlight that packaging design is seen as various blended elements that are designed to achieve a particular sensory effect. Bruce and Daly (2007) state that design increases products value and their organisations. The aforementioned researchers state that packaging designs add to the creativity, intellectual property and competence of the company. Orth and Malkewitz (2008) argue that package design is an incredibly significant medium because it has such a huge impact on a consumer's decision making. The package is what the consumer sees and helps make his/her decision to purchase. Marketers and designers can provoke different behaviours from consumers based on the designs of their packages. The final aim of the packaging is to get the consumer buying the product.

\subsubsection{Consumer Behaviour}

Belch and Belch (2002) define consumer behaviour as a set of the activities that a consumer experience in searching for better prospects and this involves namely; searching for, selecting, purchasing, using, evaluating the product. It can also be a process undertaken by consumers to select, purchase, use, or dispose products, services, ideas, or experiences to satisfy their quest. Consumer behavior generally means the behaviour of consumer as they look for the product that they feel will satisfy their intended needs and wants. Vani et al. (2011) classified factors considered in consumer purchasing habit into those that can be controlled and those that cannot be controlled. Controllable factors include mainly the 4Ps whilst uncontrollable factors encompass demographic, socio economic, cultural, geographical and psychological factors.

\subsubsection{FMCG defined}

Deliya and Parmar (2012) define FMCGs as goods that normally bear a low price and is sold fast. These products are charaterised by low profit margins although cumulative profits might be high based on large quantities sold. It is envisaged that FMCGs have an immediate turnover, and prices are relatively low and that these FMCG products have a quick shelf turnover, relatively low cost and do not need much financial investments. FMCGs include non-food items and consumables that are usually bought by many consumers for their daily usage for example groceries, toiletries, teeth cleaning materials, on the other hand non-durable products such as light bulbs, batteries, paper products and plastic goods. These products are normally found in grocery stores, supermarkets, hypermarkets.

\subsection{Theoretical Literature Review}

In this paradigm shift, the customers are demanding more value for their money and as such they are now reacting differently from the old ways. They have different perceptions about a product make up and have developed complicated perceptual scales that determine what they consider before purchasing FMCG products and what not to buy at all. Material use is most preferred whilst size, shape, colour, text and graphics are less preferred. Most complicated customers suggest that more emphasis should be put on visual package elements, development of innovative packages, aesthetic components that are soothing for the eyes and that labeled information must be accurate to an extent that consumers would understand it easily.

In Zimbabwe the companies in the FMCG sector are struggling to copy up with imports that are coming with advanced quality packaging technology. Customers are usually influenced to buy those products as a result of the outward look of the product. Packaging is being taken as a form of marketing to influence consumers. Khan (2007) asserts that business managers tend to diminish the value of creative marketing on their products and pay no particular consideration to the competitive environment. In simple terms, marketing has become an unfamiliar terrain and as a result insufficient time is allocated to this vital function. It should be noted that an improved insight into market-related issues such as increased competition, limited market size, low demand for products and ineffective marketing is a vital factor for business success (Kapoor et al., 1997). Kotler (1999) however suggests that to prevent the biggest mistake of having poor marketing strategies or efforts, an organisation should conduct marketing audits to review whether their strategies are still in line with the marketing environment. 
Change of technology has become a major threat to the local FMCG manufacturing sector in Zimbabwe. After the economic crisis in 2009, a number of Zimbabwean industries in the sector were at the verge of collapse. Since then, there has been a growing concern about the effect of technological change on the work of companies in undeveloped countries, however Zimbabwean companies had bigger issues at hand since they were struggling to survive as they were not able to upgrade their technology and machinery to match up with competitors in the region like South Africa for example.

Blanchard (2006) is of the view that determinants of imports are a part of domestic demand that falls on foreign products. The aforementioned researcher asserts that this depends on domestic income. Furthermore the researcher asserts that an increase in domestic income leads to a higher demand for all goods that is both local and foreign goods where this translates to what is known as higher domestic income, leads to higher imports. However Blanchard (2006) also notes that although high domestic income translates to higher demand and ultimately high imports, there is also an issue of price where consumers may buy foreign products or services because they bear a favourable price than that of domestic products or alternatively that the foreign goods may be attractive than those manufactured locally.

In view of Rice (1997) a good package should be characterized by the following:

1. Attractiveness: the package should be attractive and fascinating to draw customer's attention. Attractive packaging stimulates, thus packaging can dramatically influence customers' minds hence some end up demanding the product due to its attractive package.

2. Economical: A good package should be economical. Costly package increases the price of the purchased component

3. Protective: A product should be packaged neatly so that quality, quantity and colour of the components does not decline thus it should be insulated from damage by rain, dust or insects. Proper package should ensure no damage or spillage during transportation.

4. Communicative: A good package should provide information about quantity and brand utility of the merchandise

5. Convenient: The package should allow free and easy movement of the product from one place to another. The shape and package size should also be compatible with retailers and wholesalers for shop or for consumers to keep at home. The package should preferably be re-usable.

6. A good packaging should reflect the conditions in which the product should be sold.

7. Packaging needs to highlight compelling and believable claims on product differences.

\subsubsection{Background Information of Packaging}

Prendergast and Pitt (1996) assert that packaging is a crucial factor in purchase decisions. Rettie and Brewer (2000) further highlight that it forms a vital part of the selling process. Silayoi and Speece (2004) highlight that a lot of customers regard the package as part of a product but went on further to highlight that different consumers respond differently to packages depending on the involvement level. Kotler (2002) is of the view that packaging draws consumer attention to a brand and enhances its image. Underwood et al. (2001) state that packaging gives a noticeable value to products and works to guide for differentiation. Alternatively, Rundh (2005) is of the view that packaging influences consumer's perceptions about the product. Speece (2003) states that packaging is critical for customers and that it must communicate the advantages salient to a product inside. The aforementioned researcher highlights that customers are becoming more careful shoppers and are taking notice of packaged FMCG products. Packaging comprise of different elements. Smith and Taylor (2004) confirm the six variables that producers and designers must take into consideration when creating efficient package and these are form, size, colour, flavor, material and graphics. Underwood (2003) however distinguished packaging elements as two blocks that is graphic elements which include typography, colour, shapes used, and images furthermore, structural elements which include size, form of the containers, and materials. Rettie and Brewer (2000) highlight that elements that instill verbal stimuli can be recalled better when placed on the right-hand side of the package and those that trigger non-verbal stimuli on the left-hand side thus pictorial elements on the left-hand side of the package helps to maximize consumers' recall ability.

\subsubsection{Background Information of consumer buying pattern of FMCG Products}

There is a general agreement among many researchers that the behaviour of consumers towards FMCGs is the same despite cultural differences (Speece, 2000).The researcher highlights that understanding issues that concern consumers in one sophisticated market should provide a useful guide for others. Kotler et al. (1996) highlight that most FMCG products are low involvement products and consumers avoid searching extensively for information, evaluate characteristics and make considerable decisions on which one to buy. One reason for this kind of a norm by customers could be that the item is viewed as simply not very important. McWilliam (1997) is of the view that lack of sufficient research by the customers' lead to their failure to recognize leading brands resulting in consumers switching from one brand to the other.

\subsubsection{Approaches to the Buying Behaviour of consumers}

Bray (2008) confirm that there are a lot of different mechanisms that have been accepted in trying to explain how consumers behave when they intend to purchase products thereby drawing on differing traditions of psychology. These approaches determine how a consumer behaves. The approaches include psychodynamic, cognitive, economic man, behaviourist and humanistic approaches. Different researchers have different opinions on how these mechanisms contribute to the behavior of the consumer as explained below. 


\subsubsection{Economic Man Approach}

Bray (2008) highlights that early proponents feel that man is entirely rational and self interested, making decisions based upon the ability to maximize utility whilst expending the minimum effort. The approach suggests that man should exhibit a rational behaviour in the economic sense. However for man to behave rationally a comprehensive research on alternative product should be done so as to have options on which to base the selection decision and be able to rank the alternatives properly while at the same time be able to select the optimum course of action. Simon (1997) is of the view that the selection criterion highlighted above no longer holds water as many consumers rarely look for sufficient information to base their decisions, it is time consuming to search for reliable information to make such perfect decisions and as such consumers are influenced by social relationships and values. 'Herbert Simons Satisfying Theory' argues that, individuals are often described as seeking satisfactory rather than optimum choices (Simon, 1997).

\subsubsection{Psychodynamic Approach}

Bray (2008) highlights that this approach is associated with behaviour which is subject to biological influence through 'instinctive drives' which operates outside of conscious thought. Freud identified the psyche, namely the ID, the Ego and also the Superego. The ID component consists of the unconscious psychic that operates to fulfill basic urges, desires and needs. It is guided by the pleasure principle which seeks an immediate fulfillment of needs. Ego is the state of awareness which thinks of you as different from another. Ego never thinks about what is but what was and what could be. The super ego seeks to explain the moral values and natural skills acquired from parents and the society that guide how an individual behaves. These provide guidelines to an individual to sense wrong and right when making decisions. The major idea based on psychodynamic is that, what influences a human behavior are biological drives not individual cognition or environmental stimuli Bray (2008).

\subsubsection{Behaviourist Approach}

Bray (2008) assert that behaviourism is a family of philosophies and is explained by external events and all things that organisms do including feelings, thoughts and actions can be seen as behaviours. What influences people to behave the way they do are linked to the external factors of an individual Bray (2008). The most influential proponents of the approach to behaviour were Ivan Pavlov who studied classical conditioning and Burrhus Skinner who worked on operant conditioning. Skinner (1938) argues that behavioural research is still contributing to the concept of how human behave. Bray (2008) concluded that behaviourism does not appear to adequately contribute to the great diversity of response generated by a population exposed to similar or even near identical stimuli.

\subsubsection{Cognitive Approach}

This term ascribes observed action (behaviour) to intrapersonal cognition whereby the individual is viewed as an information processor. Intrapersonal causation challenges the environmental stimuli in consumer behaviour but however an influential role of the environment and social experience is acknowledged, with consumers actively seeking and receiving environmental and social stimuli as informational inputs aiding internal decision making. Cziko (2000) acknowledges that the cognitive approach is helpful in aiding knowledge to the field of consumer decision making. The aforementioned researcher confirms that consumer behaviours have been further explained with the development of the Stimulus-Organism-Response model by Hebb during the 1950s.

Early Stimulus-Organism-Response models like the one depicted in Fig 2.1 suggest a linear relationship between the three stages with environmental and social stimuli acting as external antecedents to the organism. This approach assumes that stimuli act upon an inactive and unprepared organism. However most modern theorists now acknowledge that information processing is conducted by an active organism whose past experience will influence not only the processing of such information but even what information is sought and received.

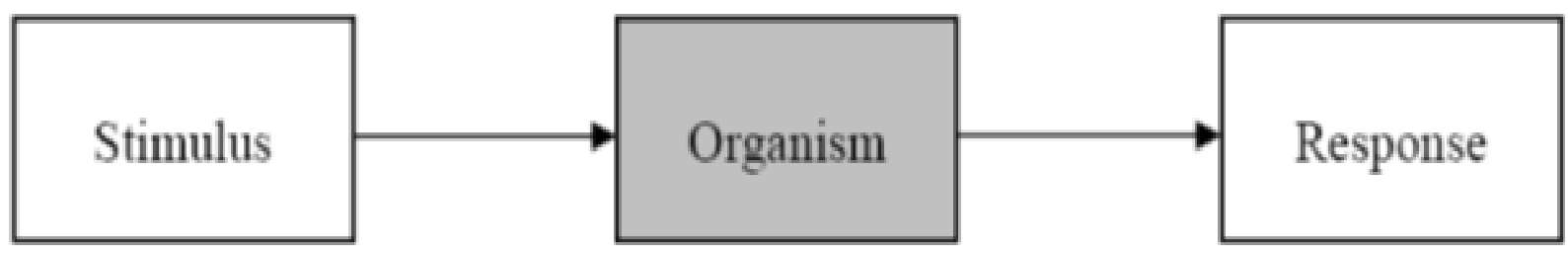

Source:Cziko (2000)

Fig-2.1. Stimulus-Organism-Response model

Hence information processing will be both stimulus driven and concept driven (Moital, 2007). This development suggests a more recent explanation of how a consumer make decisions and has been cited to be circular in fashion or can be illustrated through a Venn diagram (Jacoby, 2002).

\subsubsection{Humanistic Approach}

Cognitive models are believed to be one of the most important models in explaining the concept of consumer motivation in making purchasing decisions, however a number of academics have exposed its weakness in their endeavour to come up with solid humanistic ideas that explain the behaviour of the consumer. This approach emphasize that people are capable of controlling their life and therefore will make decisions that will enrich their personal goals to realize their self-fulfillments and personal growth.

\subsubsection{Packaging Design on Consumer orientation towards FMCG Products}

Packaging is viewed as a composite of elements, thus it cannot be taken lightly since there are so many components that constitute packaging. Others have considered the following elements namely; graphics, shape, size, 
printed information and innovation as components of a package. Underwood et al. (2001) assert that for an individual to ascertain the effect of packaging on consumer behavior, there is need to study the role played by each element and observe how it affect consumer choices. Packaging design should be conspicuous so as to attract customers causing them to form impressions towards it. Silayoi and Speece (2004) highlight that the features on a package clearly demonstrate the state of the product inside in terms of its quality and originality. Hence, consumers associate the external features of the product with the quality and translate this into decision making. Packaging design communicates favourable or unfavourable implied meaning about the product. Underwood et al. (2001) consumers imagine the product and associate it with tastes, feels, smells, or sounds and this evokes their purchasing intentions. In some instances, some scholars generally use the holistic approach to packaging designs and claim that all the elements on a package affects purchasing intentions the same, this may not be the case considering the below arguments.

\subsubsection{Graphics}

In view of Silayoi and Speece (2004) graphics includes layout, colour combinations, typography and product photography all of which form the packaging designs. FMCG products are classified as low involvement products and in some instances evaluation of attributes is of less importance in low involvement decisions hence graphics and colour become critical. Consumers usually learn colour associations and these lead them to prefer certain colours for various product categories. A colour used on package is believed to play a significant role in stimulating purchasing intentions and consumers' perception of the product's attributes is based on the colour on its packaging. Silayoi and Speece (2004) state that colour can be a potential cue on a package which customers can associate the product with especially if the brand is unique. Madden et al. (2000) highlight that different cultures have different colour associations and hence their preferences are biased towards their culture's associations. Deliya and Parmar (2012) are of the view that different colours on packages set different moods among customers.

\subsubsection{Package Shape and Size}

Package size, shape are deemed to affect judgment and decision making (Silayoi and Speece, 2004). More elongated packages are regarded as larger and when these products are purchased customers experience true volume (Silayoi and Speece, 2004). Raghubir and Krishna (1999) confirm that disconfirmation of package size after consumption may not lead consumers to revise their volume judgments especially if the difference is insignificant. Different sizes appeal differently to different involvement levels. Deliya and Parmar (2012) pin point that in cases where product quality is hard to determine, packaging size has a great effect on what the customer purchases.

\subsubsection{Printed Information}

Consumers with high involvement are insignificantly influenced by image issues and visual response. Hence these people concentrate much on the information that is written on the package. Accordingly, Silayoi and Speece (2004) state that information written on the package helps consumers in planning which product to consider for their purchasing. However, information on a package may mislead through over emphasizing thereby causing confusion through giving inaccurate information. A way to reduce confusion is that consumers reduce their choice of alternatives and evaluative attributes as suggested by Deliya and Parmar (2012). However this strategy is said to work for experienced consumers as heavy users usually do not compare to get the best brand alternatives. Hausman (2000) also states that consumers who regularly search for product information develop a bank of information for each product and this makes them to be well informed and restrict further search in their next purchase. Vakratsas and Ambler (1999) highlight that more highly involved consumers evaluate message information and rely on message argument quality to form their attitudes and purchase intentions. Deliya and Parmar (2012) give a general conclusion that, consumer with low involvement usually purchase without carefully examining brand and product information.

\subsubsection{Innovation}

Silayoi and Speece (2004) highlight that technology developed for packaging comes from the current trends in products and consumer behaviours. Packaging innovation in this dynamic environment must be consumer oriented, meet the green marketing agenda, meet the nutritional requirements of the society, must be efficiently manufactured, and should have a long shelf life and meet food safety requirements of the people. Silayoi and Speece (2004) are of the view that technology that comes in with a package plays a big role and thus forms a special form of informational element. Deliya and Parmar (2012) are of the view that innovative packaging increases the value of the goods if it meets a consumer needs. In most instance customers accept a product if its package is well innovated, thus product innovation plays a pivotal role in consumer decision making of FMCG products. As part of product innovation font style is also important. Deliya and Parmar (2012) affirm that font style of packaging grabs customer attraction. There is need to create mind blowing and attractive font styles in order to lure more customers. Usually an attractive package has innovative font style and attracts consumers. According to Deliya and Parmar (2012) high quality packaging material attracts consumers.

\subsubsection{Roles of Packaging}

According to Lee and Lye (2002) there are basically five functional roles that are performed by packaging. These are depicted below on the diagram. 


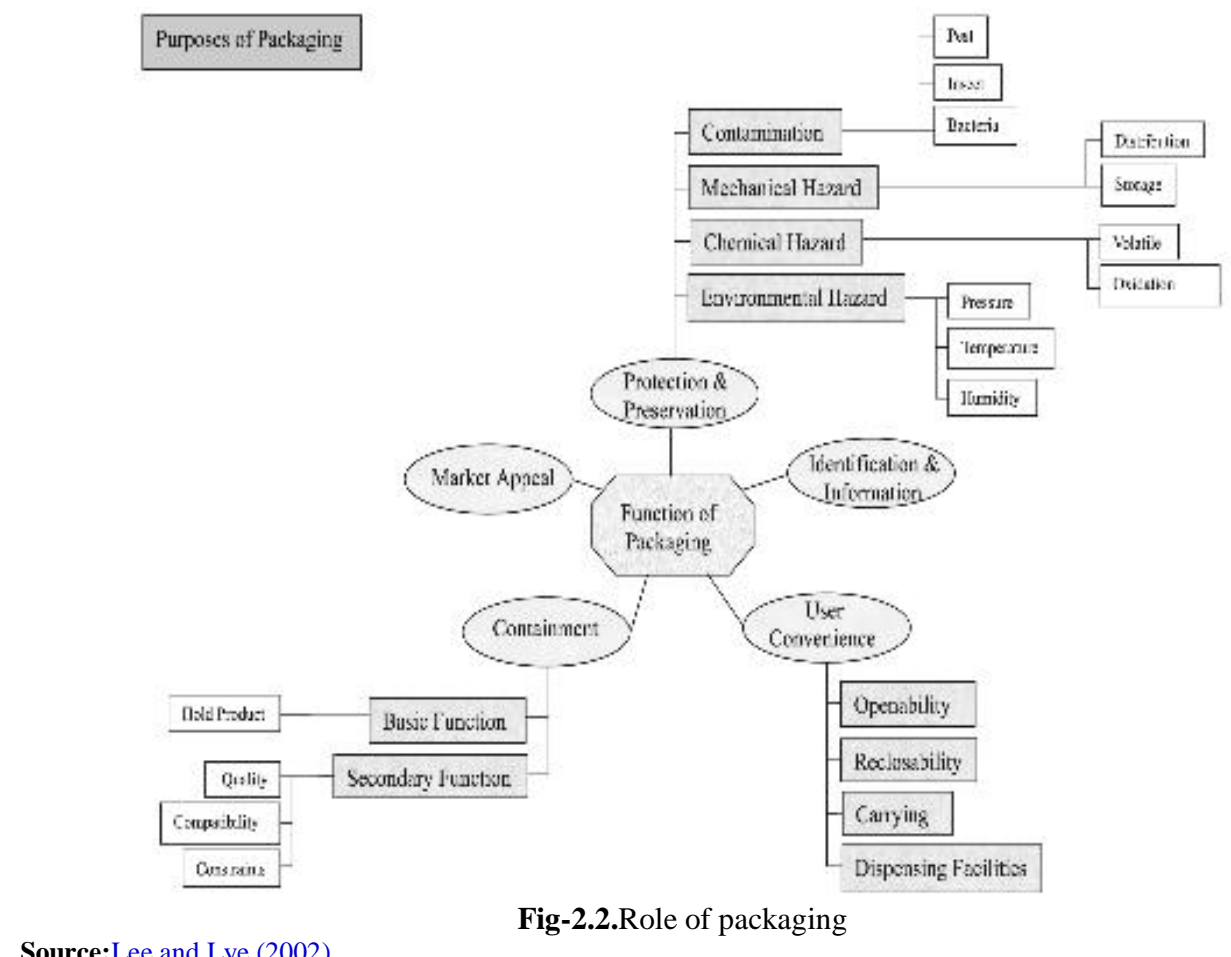

\subsubsection{Protection and Preservation}

Lee and Lye (2002) assert that protection and preservation are roles of packaging. These involve protection from environmental, mechanical and chemical poisoning and also form contamination. Deliya and Parmar (2012) highlight that packaging provides physical protection of the objects from shock, vibration, compression and temperature. In the same line, Deliya and Parmar (2012) assert that if the product is safeguarded from becoming dirty or avoiding smudging customer hands through contamination then it is said to be a clean package.

\subsubsection{Market Appeal}

Lee and Lye (2002) identified market appeal as another role of packaging. This is to say that packaging helps in improving people's perception about the product. Packaging is used to get the consumer's attention, promote and convey messages about the product's attributes whilst still on the shelf.

\subsubsection{Convenience}

Another role of packaging is to add convenience in distribution, handling, display, sale, opening, reclosing, use, and re-use (Deliya and Parmar, 2012). Lee and Lye (2002) describe the convenience offered by packaging namely; openability, reclosability, carrying and dispensing facilities. Packaging enables to carry out groupage where fragmented objects can be transported from one place to the other in one package, thus ensuring handling efficiency.

According to Deliya and Parmar (2012) packaging reduces theft as once opened a package cannot be re-closed or gets physically damaged that is it shows signs of opening and is helpful in the prevention of theft. In this case packaging provides opportunities to include anti-theft devices.

\subsubsection{Helps in Identification}

Lee and Lye (2002)state that packaging helps in identification and provision of information to customers. Thus, a good packaging must contain valuable product information that consumer may need to know, information on how to transport, use, recycle, or dispose of the package or product is often contained as a label on the package.

\subsubsection{Empirical Evidence}

Deliya and Parmar (2012) carried out a descriptive study in Patan District of Gujarat (India) about the roles of packaging in stimulating the behaviour of the consumers, their aim was to discover the relationship between independent variable and dependent variables. Samples of 150 were chosen to represent respondents. The research revealed that packaging is the greatest factor and that consumer decision making is dependent on it. Furthermore, it was discovered that packaging, the colour, background image, and packaging material, innovation, design of wrapper, printed information and font style were taken as predictors in consumer behaviour. The study concluded that package could be treated as one of most valuable tool in today's marketing communications, necessitating more detail analysis of its elements and an impact of those elements on consumers buying behaviour. Deliya and Parmar envisaged that appropriate and vivid picture or packaging colour which delivers a happy feeling or an easy handle/open/dose/dispose package shape contributed to catch consumers' attention and interest. For this purpose the main packaging elements could be identified as graphic, colour, size, form. Similarly, material of packaging such as wrapper design, printed information, and innovation are all ingredients to product success in the market.

\subsection{Factors Influencing Consumer Buying Behaviour}

Vani et al. (2011) highlight that these factors can be classified as controllable and uncontrollable. Controllable factors are mainly the 4Ps. Uncontrollable factors are those that an organisation have no control and include factors like demographic, socio economic, cultural, geographical and psychological factors among others. 


\subsubsection{Controllable Factors}

\subsubsection{Product}

Vani et al. (2011)affirm that product characteristics that includes attribute, taste, colour, quality, product knowledge and innovation, ingredients and brand image affect decision making. Attributes of a product are important to consumers because they are the ones that deliver the benefits that consumers are seeking from the products. Angela (2006) highlights that taste of the product also influences consumer buying behaviour. However, results from Angela study showed no significant results on brand preferences because of different tastes that consumers have. Colours just like words have been viewed by conveying ideas that prompt buying. Vani et al. (2011) adds on to this view by highlighting that colours can be taken to be symbols which express definite meanings. Vani et al. (2011)further pin point that the meaning of a particular colour may depend largely on individuals culture or their economic social status. Product quality motivates customers to make a purchase. However product quality is viewed differently by many consumers and this sense, it is arguably that customers judge the degree of quality basing on the period of time of product usage. Therefore consumers' perception of quality determines their decision-making process. Product innovation is also another factor contributing to consumer buying behaviour. Shopping innovativeness is described as a tendency to try new products and brands. Ingredients have also been identified as a factor that influences buying behavior. However, brand image is an extrinsic value of a good and is perceived to have less impact compared to intrinsic attributes. Brand image should be considered as a consistently risk reliever before planning for a buying decision. Consumers are strongly oriented toward products with brand image than toward products with no brand image (Belch and Belch, 2002).

\subsubsection{Price}

In view of Smith and Carsky (1996) in today's markets, price is the most salient factor contributing to making choices. Assuncao and Robert (1990) is of the view that when faced with a buying decision in a product category consumers observe a price and considers their current budget position towards that product before making a purchase decision. In most cases when a consumer is exposed to alternatives there is a tendency to select a product that maximizes greatest utility based on the available brands. Price alone in the absence of other cues is a powerful contributing factor in considering how the brands were perceived. Consumers face brands with varying prices and perceived quality levels and they make a choice consistent with the relative value attached to both attributes.

\subsection{Place}

Vani et al. (2011) state that the place where the merchandise is found plays a vital role in determining product acceptance in the market and the behaviour of the consumer towards it. In this regard, place becomes critical as consumers considers consumers considers where the product is being sold when making purchasing decisions. Customers expect the availability of the product at the time and place where they want and not when and where the supplier wants to deliver. Suppliers have to link their manufacturing plans to the demand of the customers but however this can create uncertainty in production planning of some marketers but winners' know that it is important to meet demand in different markets that will set them apart from others. Hence place is a determining factor in consumer buying patterns as customers will buy if they get the product where they want it not where the supplier wants.

\subsection{Promotion}

Promotion is how people get to know about your product. This includes advertising, direct marketing, sales promotion and public relations. Advertising play a crucial role on consumer brand preference. Consumers tend to buy products that they have seen being advertised. Direct marketing greatly influences the buying behaviour as marketers will be having a platform to communicate their product's composition and hence convince customers to buy. Shimp (2003) states that sales promotion describes incentives induced by a manufacturer to increase trade with consumers. Promotional incentives are used to encourage desired behaviours from consumers. However, Vani et al. (2011) highlight that sales promotion is short-term oriented and capable of influencing consumers behavior.

\subsubsection{Uncontrollable Factors}

\subsection{Social and Cultural}

Culture is learned behavior that is passed to an individual, reinforced through the family and through educational and religious institutions, this becomes part of the behavior over time. Cultural influences are powerful and determine the success of any product in a market, companies that fail to recognize the value of culture in a society will never become successful, rather will dream success which will never be realized, and under such circumstances it will be difficult to develop products and market them successfully in those markets. Sub cultures also exist and they influence the buying patterns of consumers. Managers must recognize the following cultural elements namely; linguistic differences, geographical, religious beliefs if they want to succeed in foreign markets and must recognize these as providing opportunities rather than posing problems.

\subsection{Social Class}

This is the most prominent social influence. Income is a well known as the chief determinants of social class. High income earners spent more on luxurious goods and services and are considered to be on a higher social class while those who earn less are perceived to be of lower class. The life styles of these two groups, the way they spent money, their needs and wants are also different. The behavior of these consumers towards making purchase decisions is quite different. Higher social class is price insensitive while the opposite is true for lower class that is price sensitive. The higher social class is quick to make purchase decisions and usually they buy in large quantities and in hypermarkets where there are minimum queues while the lower class takes time to make purchase decisions and they 
buy in smaller quantities which they afford in busy supermarkets where queues seem to be insurmountable. Classification of consumers on the basis of life style is becoming more meaningful today according to Vani et al. (2011). However whatever income level consumers reach during lifetime, their basic attitudes and preferences do not shift radically.

\subsection{Personality and Self Concept}

Personality and self concept also influences consumers when making decisions whether to buy a product or not. This means how people think and how other people see them and how they relate altogether. Marketers are so particular about this behaviour since it is linked to the consumption patterns. The personality of an individual is enduring, it does not change in a matter of hours but last longer for years, and for example an extrovert consumer is outgoing while an introvert is the opposite. Such personalities do not vanish in abrupt. A number of purchase decisions reflect the personality of an individual and therefore marketers must take note of personalities when making marketing appeals. Bray (2007) asserts that psychological theory suggests that we are born with instinctive desires which cannot be fulfilled in a socially acceptable manner and are thus repressed. The purpose of marketing in this regard is to appeal to inner needs whilst delivering products which enable them to be satisfied in a socially acceptable way.

\subsection{Attitudes}

The more influential attitudes usually come from the family members and friends or close associates. More refined attitudes develop later. In the field of marketing, the total of attitudes is seen as the total set of cognitions that a buyer has in relation to a potential purchase or a purchasing environment. This is why some companies take their time to study consumer attitudes to increase their loyalty towards their particular brand or product Bray (2008). An attitude is the most ruinous thing since once attitude has been formed in the mind of the consumer it might be difficult to alter. Even a small dissatisfaction can cause a fundamental shift in disposition. Thus attitudes influence the buying behavior of consumers.

\subsection{Learning}

Learning is very crucial in influencing the buying behavior of consumers, a consumer who has experience with a product either through previous usage or through gaining information through peers has already developed perceptions towards a product and if this consumer is not handled properly may course company misfortunes. When the customer perceives that a certain product is consumed more by his reference group, then that product experiences repeat purchase to reinforce its acceptability within the group. Hence learning influences consumer buying behaviour. In this regard, learning can also be viewed as information received through advertising, other publicity or through some reference group or other means. Companies should be advised that a consumer today is well informed through learning and therefore his/her behaviour should be modified to the benefit of the company. Failure to do that will result in customers shifting to the competitor.

\section{Summary of Findings}

\subsection{On Consumer Buying Behaviour}

The researchers discovered that packaging elements affect the buying pattern of consumers on FMCG products shown by printed information with $93.75 \%$ from respondents.

Background image, colour and font style also play a part in influencing consumers. Font style however has the least effect as it only scored $31.25 \%$. This corresponds with Deliya and Parmar (2012) study which concluded that font style has the least effect as compared to all the package elements.

\subsection{On the Role of Packaging on FMCG Products}

From the research findings it was revealed that protection is the main purpose of packaging FMCG products as highlighted by $63 \%$ of questionnaires ticking that packaging provides protection to a greater extend. Protection as a role of packaging was also highlighted by $100 \%$ of interviewed respondents thereby showing that it is the main role of packaging. Convenience in terms of opening, storage and handling is also another purpose that is served by packaging as evidenced by $50 \%$ responses from questionnaires, while $66.67 \%$ of the interviewed policy makers mentioned it second. Preservation is also offered by packaging to a rather lesser extend because at times the products are found not to have been preserved well though they will be enclosed in their packages.

\subsection{On other Factors that Affect Consumer Buying Behaviour}

Factors affecting consumer behaviour can be controllable or uncontrollable to firms. On controllable factors, the organisation can alter the factors to suit requirements of customers. Uncontrollable factors are difficult to control. Price has been considered as one of the leading factors affecting consumer decision making as indicated by $93.75 \%$ respondents and $100 \%$ of interviews confirming its importance. Quality follows with $81.25 \%$ of questionnaire responses saying that it influenced buying behaviour and also $66.67 \%$ of interview responses rating it second. Promotion on products is considered not that important to customers and the least factor that is considered by customers is place which is where the product is found, only $46.88 \%$ of the questionnaire responses being yes and $33.33 \%$ of interview responses highlighting that place is considered when consumers are making decisions.

Uncontrollable factors that influence the buying behavior of consumers include socio-cultural, learning, personality and self concept, attitudes and social class. It was revealed that the socio cultural environment factor has minimum influence on the purchasing behavior of consumers which had only $9.38 \%$ of questionnaire respondents dismissing that it has an influence on buying behavior. Learning is next important with $78 \%$ that is 25 respondents of questionnaires saying that it has an influence and also $100 \%$ of the interviewees. Personality and self concept follow. 
The least factor that have a bearing in the consumer's choices is social class with $84.38 \%$ of questionnaire respondents rejecting that it has an influence on buying behaviour and $66.67 \%$ of the management interviewed saying it has a bearing on buying behaviour. The major factor that was highlighted is that, during the hyperinflationary period consumers never took packaging seriously but were mainly concerned about the availability of the product from the shelf.

\section{Recommendations}

The researchers suggested the following recommendations.

- It is recommended that the companies must prioritize investing in packaging technology as this will enhance competitiveness of their products.

- In line with the conclusions drawn by the study, the researchers recommend that the firms in the FMCG

- FMCG managers are recommended to use mostly preferred labels in their marketing appeals. Basically the labels placed on products should describe where it was made, when it was made, what it contains and how to utilize it, dates when their products expire. In addition the researcher recommends that companies that are in the FMCG sector should use clear labels that are easy to understand.

- The researchers also recommend that when designing packages, designers of the manufacturing firms must ensure that the package protects the product inside to a greater extend as this is considered to be the main role of packaging.

- The researchers also recommend that FMCG manufacturing firms should competitively price their goods without compromising on quality if they are to be successful and win the consumers' minds

- The socio-cultural environment need to be greatly considered and the researchers recommend that firms should differentiate their product packaging designs to conform to the target market

- The researchers also recommend that firms take packaging complaints from customers seriously and also they should create a platform for feedback from customers concerning their products

- Locally financially distressed companies should be empowered especially the SMEs (engine for economic growth) to produce products with appealing packages for Zimbabwean supermarkets.

\section{References}

Angela, M., 2006. Speech at the world economic forum, Davos, Switzerland. Available from http:// www.bundesregierung.de/nn_6566/Content/EN/Reden/2006/01/2006-01-25-speech-by-angela-merkel-chancellor-of-the-federalrepublic-of-Germany-at-theworld-economic.fo.html.

Arens, F.W., 1996. Contemporary advertising. Irwin, United States of America: Mcgraw-hill Higher Education.

Assuncao, J. and M.J. Robert, 1990. The rational effect of price expectations on sales-price relationships. Marketing Studies Center, John E. Anderson Graduate School of Management, UCLA, Working Paper No. 199.

Belch, G.E. and M.A. Belch, 2002. Advertising and promotion: An integrated marketing communications perspective. 6th Edn., New York: McGraw-Hill.

Blanchard, O., 2006. Macroeconomía. 4th Edn., Madrid: Prentice Hall Ibérica.

Bray, J., 2007. Consumer behaviour theory: Approaches and models. 1-33. Available from http://eprints.bournemouth.ac.uk/10107/1/Consumer_Behaviour_Theory_-_Approaches_\%26_Models.pdf [Accessed 02/11/2016].

Bray, J.P., 2008. Consumer behaviour theory: Approaches and models. Discussion Paper. Bournemouth: Bournemouth University.

Bruce, M. and L. Daly, 2007. Design and marketing connections: Creating added value. Journal of Marketing Management, 23(9-10): 929953.

Cziko, G., 2000. The things we do: Using the lessons of bernard and darwin to understand the what, how, and why of our behavior. Congress Cataloging.

Deliya, M.M. and J.B. Parmar, 2012. Role of packaging on consumer buying behavior-patan district. Global Journal of Management and Business Research, 12(10): 49-67.

Hausman, A., 2000. A multi-method investigation of consumer motivations in impulse buying behavior. Journal of Consumer Marketing, 17(1): $403-426$.

Jacoby, J., 2002. Stimulus-organism-response reconsidered: An evolutionary step in modeling (Consumer) behavior. Journal of Psychology, 12(1): 51-57.

Kangasharju, A., 2000. Growth of the smallest: Determinants of small firm growth during strong macroeconomic fluctuations. International Small Business Journal, 19(1): 28-43.

Kapoor, K., D. Mungwara and I. Chidavaenzi, 1997. Empowering small enterprises in Zimbabwe. World Bank Discussion Paper No. 379. Washington D.C.

Khan, 2007. Consumer behaviour. New Age International.

Kotler, P., 1999. Gary Armstrong principles of marketing translates Ali Pars Aeian. Tehran: Press Adabestan.

Kotler, P., 2000. Marketing management. Upper Saddle River, New Jersey: Prentice-Hall.

Kotler, P., 2002. Marketing management. New Delhi, India: Prentice Hall.

Kotler, P., S.H. Ang, S.M. Leong and C.T. Tan, 1996. Marketing management: An Asian perspective. Singapore: Prentice-Hall.

Kuvykaite, R., A. Dovaliene and L. Navickiene, 2009. Impact of package elements on consumer purchase decision. Journal of Economics and Management, 14: 441-447.

Lee, S.G. and S.W. Lye, 2002. Design for manual packaging. International Journal of Physical Distribution and Logistics Management, 33(2): 163-189.

Madden, T., J., K. Hewlett and M.S. Roth, 2000. Managing images in different cultures: A cross-national study of color meanings and preferences. Journal of International Marketing, 8(4): 90-107.

McWilliam, G., 1997. Low involvement brands: Is the brand manager to blame? Marketing Intelligence \& Planning, 15(2): 60-70.

Moital, M.L., 2007. An evaluation of the factors influencing the adoption of e-commerce in the purchasing of leisure travel by the residents of cascais. Portugal: Bournemouth University.

Orth, U. and K. Malkewitz, 2008. Holistic package design and consumer brand impressions. Journal of Marketing, 72(3): 64-81. DOI 10.1509/jmkg.72.3.64.

Prendergast, P.G. and L. Pitt, 1996. Packaging, marketing, logistics and the environment: Are there trade-offs? International Journal of Physical Distribution \& Logistics Management, 26(6): 60-72.

Raghubir, P. and A. Krishna, 1999. Vital dimension in volume perception: Can the eye fool the stomach? Journal of Marketing Research, 36(3): 313-326.

Rettie, R. and C. Brewer, 2000. The verbal and visual components of package design. Journal of Product Brand Management, 9(1): 56-70.

Rice, C., 1997. Understanding customers (marketing series: Student). 2nd Edn.: Routledge.

Rundh, B., 2005. The multi-faceted dimension of packaging. British Food Journal, 107(9): 670-684. 
Shimp, T.A., 2003. Advertising, promotion, and supplemental aspects of integrated marketing communications. 6th Edn., Boston, MA: Thomson South-Western.

Silayoi, P. and M. Speece, 2004. Packaging and purchase decisions: An exploratory study on the impact of involvement level and time pressure. British Food Journal, 106(8): 607-628.

Simon, H.A., 1997. An empirically based micro-economics. Oxford: Oxford University Press.

Skinner, B.F., 1938. The behavior of organisms. An experimental analysis. New York: Appleton-Century.

Smith, M.F. and M.L. Carsky, 1996. A comparison of involved and uninvolved consumers. Journal of Retailing and Consumer Services, 3(April): 73-80.

Smith, P. and J. Taylor, 2004. Marketing communications: An integrated approach. 4th Edn., London: Kogan Page.

Speece, M., 2000. Positioning Thai brands in developed country markets: Consumer research from Finland. Sasin Journal of Management (Thailand), 6(1): 75-90.

Speece, M., 2003. Consumer marketing in Asia for the new economy. Paper Presented at the Executive Seminar Organized by JKYL (International) Pte Ltd, Singapore, 6 November 2003 (also Presented in October 2002, August 2001, October 2000).

Underwood, R.L., 2003. The communicative powerof product packaging: Creating brand identity via lived and mediated experience. Journal of Marketing Theory and Practice, Winter: 62-76.

Underwood, R.L., N.M. Klein and R.R. Burke, 2001. Packaging communication: Attentional effects of product imagery. Journal of Product and Brand Management, 10(7): 403-422.

Vakratsas, D. and T. Ambler, 1999. How advertising works: What do we really know? Journal of Marketing, 63(1): 26-43.

Vani, G., B.M. Ganesh and N. Dr. Panchanatham, 2011. Consumer buying behaviour the controllables \& uncontrollables. International Journal of Exclusive Management Research, 1(1): 1-12. 